\title{
Childhood Synovial Sarcoma
}

National Cancer Institute

\section{Source}

National Cancer Institute. Childhood Synovial Sarcoma. NCI Thesaurus. Code C8089.

A synovial sarcoma occurring in childhood. 